\title{
International technical transfer of training systems and skills in emergency medicine and trauma management: experiences of the National Center for Global Health and Medicine, Japan
}

\author{
Akio Kimura* \\ Department of Emergency and Critical Care, Center Hospital of the National Center for Global Health and Medicine, Tokyo, Japan.
}

\begin{abstract}
For over 20 years, the National Center for Global Health and Medicine (NCGM), Japan has been involved in international assistance for emergency medicine and trauma management in many countries, including Bolivia, Vietnam, Laos, Cambodia, and Mongolia. Among the NCGM activities conducted, the most important is technical assistance for the appropriate transfer of training systems and skills in life support management. In most of the target countries, the development and execution of customized simulation training suitable for each setting has successfully motivated trainees, who are healthcare workers responsible for improving emergency medical services in their home country. Moreover, the development of appropriate training systems for trainers selected from among capable participants has played a key role in the subsequent sustained conducting of training courses independent of NCGM involvement.
\end{abstract}

Keywords: trauma system, injury surveillance, life support, essential trauma care, simulation, road traffic injuries

\section{Introduction}

A recent study reported that about $80 \%$ of the world's population reside in middle-income countries (1). When a country's income improves from lower-middle to upper-middle income, the incidence of road traffic injuries (RTIs) and other life-threatening events like heart attack and cerebrovascular accident or stroke dramatically increases because of the rapid development of motor transport and attendant changes in lifestyle. Notably, the number of deaths from RTIs reached 1.35 million in 2016 and has continued to steadily rise. If the present trend continues, RTIs are predicted to become the fifth leading cause of death by $2030(2,3)$. Currently, more people die as a result of RTIs than from HIV/ AIDS, tuberculosis, or diarrheal disease.

RTIs are at present the leading cause of death among children and young adults aged 5-29 years and the third leading cause of death of adults aged 30-44 years (3). Moreover, almost twice as many men as women die among those aged 15-44 years. This loss of the most economically productive population places an enormous economic burden on society. More than half of all RTI deaths involve vulnerable road users (i.e., motorcyclists, pedestrians, and cyclists), and RTIs are predicted to be the third leading contributor to the global burden of disease and injury by 2030 (4).

In light of this, there is immense need for international assistance to these countries. Japan is well placed to offer such assistance because the country worked to overcome this same situation during the 1970 s to 1990 s (5) by improving pre- and in-hospital emergency medical services and developing training systems.

\section{Bolivia}

The National Center for Global Health and Medicine (NCGM), formerly known as the International Medical Center of Japan (IMCJ), began international medical cooperation in the field of emergency medicine in the city of Santa Cruz de la Sierra in 1994. The IMCJ worked to establish systematic integration of emergency medical services, "Sistema Integrado de Servicios Médicos de Emergencias (SISME)", which was run by the Japan International Cooperation Agency (JICA). SISME facilitated the development of inter-hospital liaisons, life support training programs for healthcare workers as well as citizens, and an ambulance transfer system activated by the 118 emergency call system. The NCGM also developed training for emergency physicians, creating a new medical specialty in Santa Cruz.

\section{Vietnam}

Rapid economic growth in Vietnam over the last decade or so has led to an increased incidence of RTIs. Between 
2006 and 2010, RTIs resulted in 15,000 to 18,000 deaths each year in the country $(6)$, with a high proportion of traffic collisions involving motorcyclists (58\% in 2008 2009). Most of the deaths and injuries involved males (79\%) ages 15 and 49 years. Overall, $42 \%$ of RTI deaths were caused by head injury ( 6 ).

The current authors conducted a cross-sectional study to ascertain the epidemiology of RTIs occurring in the City of Hanoi (7) using City of Hanoi police reports from 2006. Of 1,271 RTIs identified, about 40\% involved people ages $20-29$ years, and $63 \%$ of RTIs were motorcycle-associated incidents. Injuries occurred at two peak times: noon to $4 \mathrm{pm}$ and $8 \mathrm{pm}$ to midnight (Figure 1). "Hot spots" of RTIs and fatalities were identified in the city area and on main roads, with no easy access to major general hospitals for RTIs occurring along the two northsouth main roads. Moreover, fatalities were significantly associated with the distance between the site of the injury and the hospital.

To help determine what assistance the NCGM could provide, the Guidelines for Essential Trauma Care (EsTC) $(8,9)$ were used to evaluate trauma care and training levels at hospitals. These guidelines were published by the World Health Organization (WHO) and the International Association for Trauma Surgery and Intensive Care to improve organization and planning for trauma care at a low cost. Items in the guidelines cover trauma care and resources, with grading for each level of healthcare: "essential", "non-essential", "desirable" and "possibly required". For example, tracheal intubation is essential for tertiary and provincial hospitals but is desirable for district hospitals and basic health clinics. In northern Vietnam mainly, medical staff were interviewed, an EsTC-based checklist was distributed, and data were collected from 3 tertiary national hospitals, 6 provincial hospitals, and 11 district hospitals in Hòa Binh Province (10). Use of the checklist indicated that the level of trauma care was quite low in district hospitals. In Figure 2, the lower part of the bars indicates the number of essential items fulfilled and the upper part indicates the number of items that are non-essential, desirable, or possibly required. Orange, blue, and green bars indicate national, provincial, and district hospitals, respectively. Horizontal lines indicate the average number of essential items required for each level of health care. Results indicated that most of the hospitals at each level fulfilled

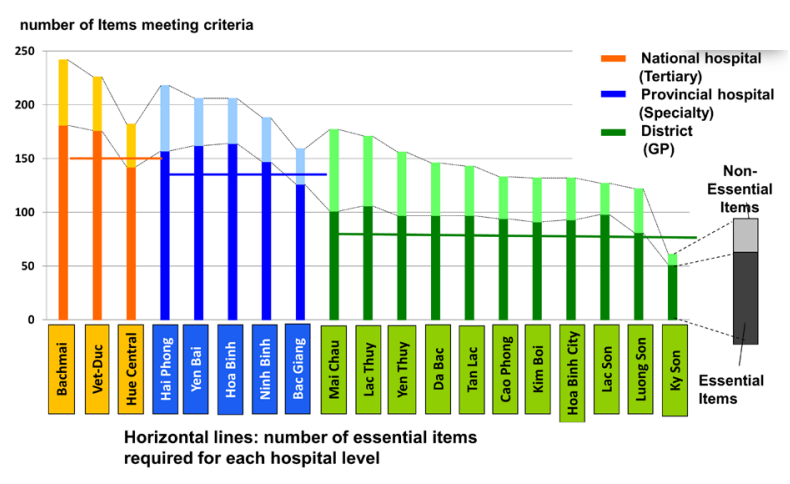

Figure 2. Survey of trauma care using the Guidelines for Essential Trauma Care (EsTC).
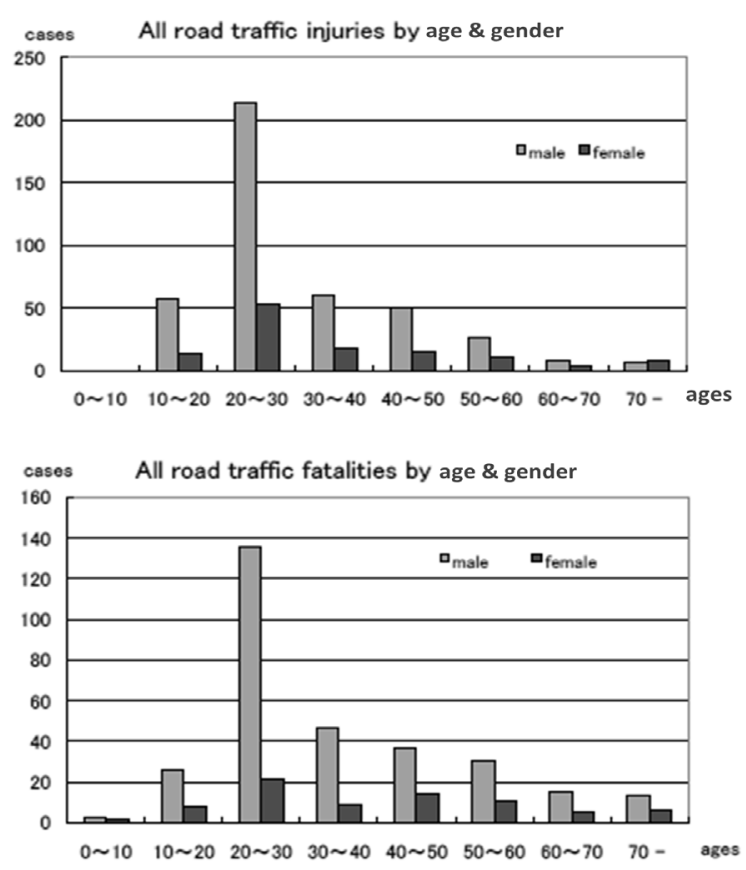
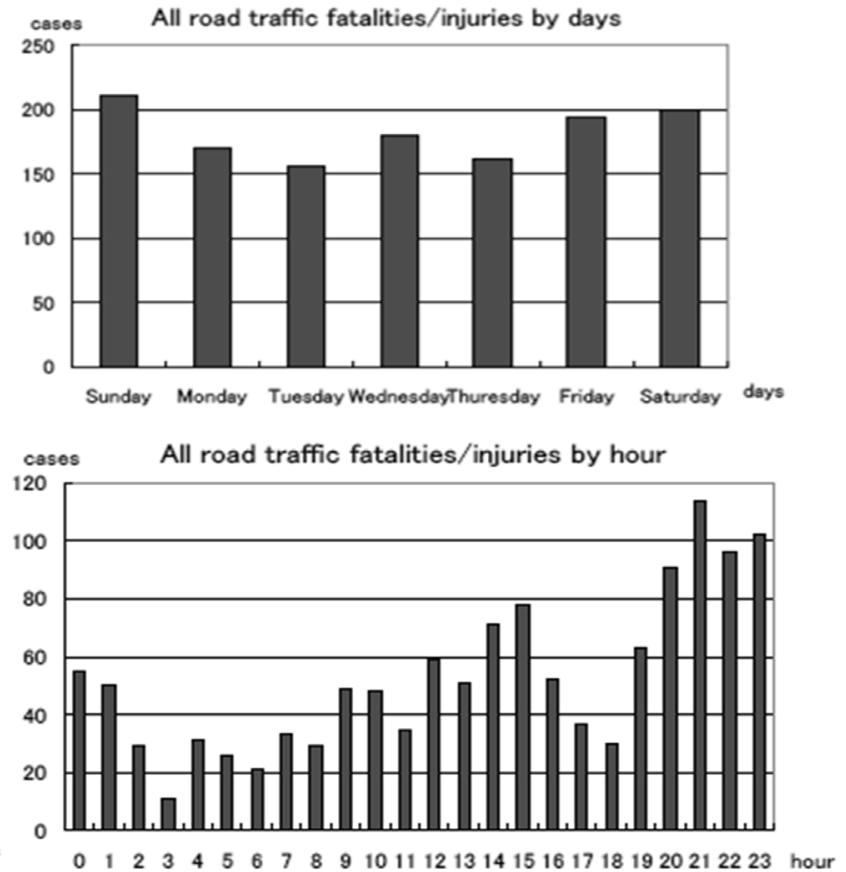

Figure 1. Distribution of road traffic injuries/fatalities in the City of Hanoi, Vietnam. 
$80 \%$ of essential items. The number of fulfilled criteria was found to correlate with total number of beds $\left(r_{s}=\right.$ $0.80, p<0.001)$ and the total number of doctors $\left(r_{s}=\right.$ $0.711, p<0.001)$. The distance to a hospital for referral was significantly correlated with equipment and supplies available $\left(r_{s}=0.69, p=0.016\right)$.

The findings from use of the EsTC checklist were consistent with the state of trauma care at each hospital. At that time, there were very few emergency physicians in provincial and district hospitals. Newly trained emergency physicians in the country were working mainly at national hospitals in major cities like Hanoi, so many patients were concentrated at, or were referred to, tertiary hospitals in the major cities rather than at medical facilities far from the scene of the accident. A higher number of items were fulfilled by Bachmai Hospital (BH) and Hòa Binh General Hospital (HGH), where JICA hospital improvement projects had already begun. In contrast, Huế Central Hospital, fulfilled a very low number of items, even lower than some provincial hospitals, despite being a national hospital.

The NCGM began providing assistance by upgrading the ambulance transfer center and emergency department at each of the 3 general hospitals and by standardizing trauma care and introducing guidelines and simulation training. Basic life support training at the national hospitals was spread to the provincial hospitals. Advanced life support training was also conducted by inviting trainees from the 3 main hospitals to the NCGM hospital in Japan (11), which was very effective in increasing their motivation to improve life support management and emergency medical system in their home country. A comparison of pre- and post-training test results indicated that most trainees had $15 \%$ more correct answers after training, which was a statistically significant increase. A questionnaire completed by Vietnamese trainees revealed that they recognized the importance of confidence in cardiopulmonary resuscitation and other related skills as well as the importance of team dynamics. Almost all trainees became interested in simulation training and wanted to be trainers. Moreover, $94 \%$ of the Japanese trainers reported being interested in the international transfer of training skills, although they experienced communication difficulties mainly due to the language barrier. After this training, standard life support training was successfully spread to surrounding provincial hospitals based on the emergency department experience gained at $\mathrm{BH}$. A challenge was also undertaken to adapt the trauma simulation training provided at $\mathrm{HGH}$ to a provincial model.

\section{Laos}

Laos is one of the lowest income countries in SouthEast Asia. As mentioned earlier, rapid economic growth and motorization usually result in high mortality from
RTIs, and Laos is no exception. There is an urgent need for improvement in the country's trauma care. To obtain basic data on RTIs, a web-based injury surveillance system (ISS) was developed based on the WHO guidelines (12) for 3 national hospitals in Vientiane that have emergency departments. A cross-sectional study (13) found that in Vientiane, as in Hanoi, accidents involving young motorcyclists riding without helmets at night were a major issue (Figure 3). To obtain better registry data, training courses in trauma data management were conducted for Laotian healthcare workers, with assistance from the Khon Kaen Trauma Center that had collaborated with several earlier studies $(14,15)$. Khon Kaen is a major city in northern Thailand located close to Vientiane. The training course seemed to be delivered much more effectively in Thai than by interpretation of the English spoken by Japanese trainers. This is because most people in Laos can understand Thai. Here again, courses in basic trauma care and disaster medicine were conducted. The workshop held with Laotian healthcare workers revealed many difficulties in ensuring sufficient funding to sustain training activities. In addition, the Internet infrastructure in Laos at that time was lacking, so the continuity needed for the ISS meant that web-based system had to be changed to standalone software that could be used offline. Using Thai in the training courses proved useful, but this option is not always available. Unfortunately, marked results have yet to be achieved in Laos thus far.

\section{Cambodia}

In 2015, road traffic accidents (RTAs) accounted for 2,265 deaths and more than 15,000 RTIs, $40 \%$ of which involved serious injuries. Since 2008, deaths resulting from RTAs in Cambodia have tended to increase and predominantly involve males $(80 \%)$. The number of fatalities was estimated to have doubled between 2005 and 2015. The largest group of road users affected was motorcyclists $(71 \%)$, followed by pedestrians $(10 \%)$. Fewer than $50 \%$ of those involved in serious RTIs are transported by emergency ambulance (16). The need to enhance the emergency medical service (EMS) system in Cambodia has increased each year, and yet the training system for emergency medicine from prehospital care to in-hospital initial management has faults and has not met this need. In 2017, 3 emergency physicians from 3 national hospitals in Phnom Penh were invited to Japan for training as medical directors. Just after their return, they entered a training of trainers (TOT) program as part of a standard pre-hospital EMS training program for 27 trainer candidates in Phnom Penh. A "medical rally" was conducted as a form of integrated training. Four outstanding candidates working at national hospitals were selected to participate. The following year, in 2018, those 4 doctors were invited to Japan to train as medical directors, and after their return home, 


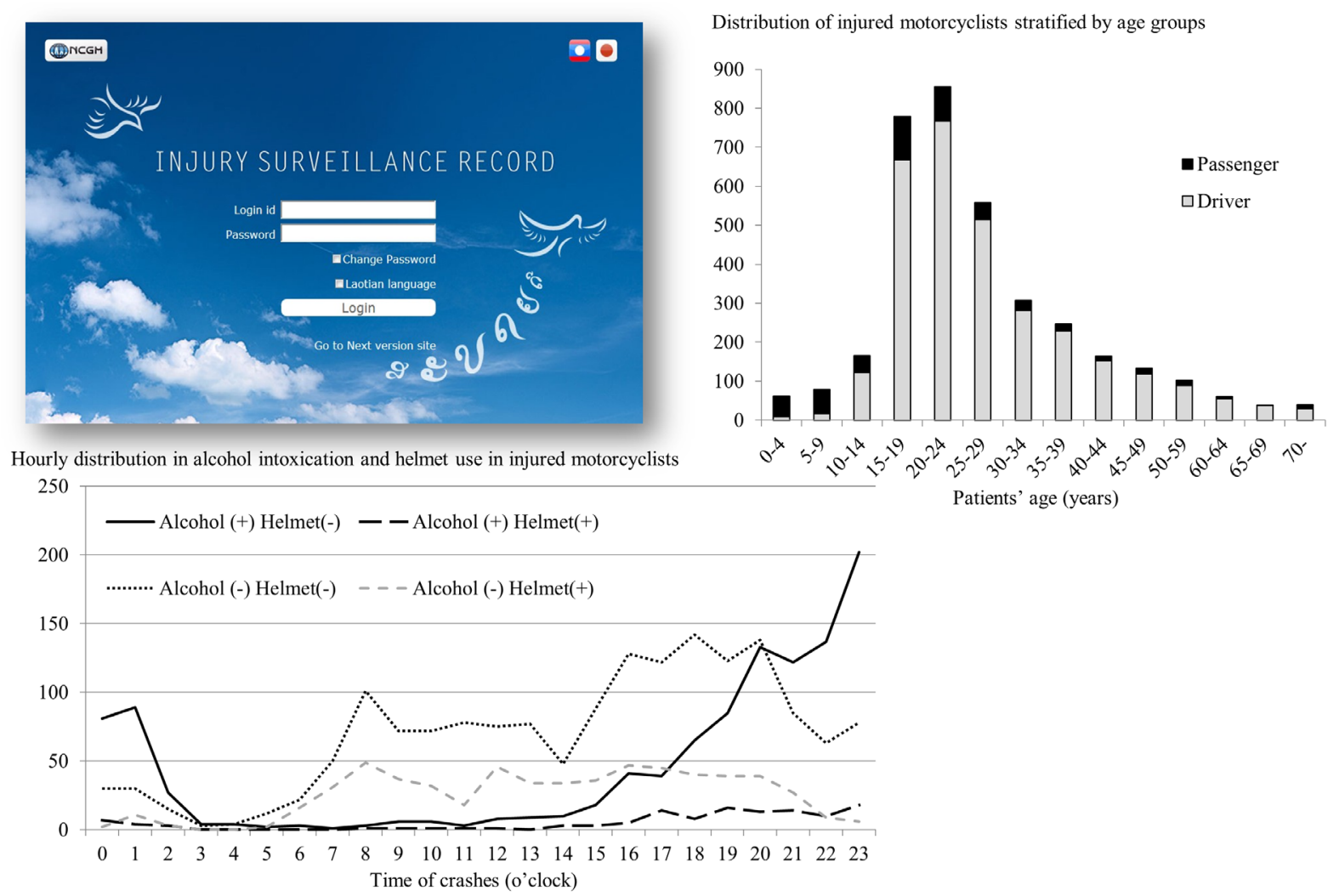

Figure 3. Introduction of the Injury surveillance system.

previously and newly trained trainers helped to conduct training in pre-hospital care and safe transfer for 25-32 healthcare workers from provincial and district hospitals in Siem Reap and Sihanoukville. In 2019, we expanded the EMS training was spread to Kampong Cham and Battambang provincial hospitals in collaboration with the now experienced Cambodian trainers. The effect of this training has been evaluated using the checklists of essential knowledge, skills, equipment, and supplies for prehospital providers (17), and the percentage of fulfilled items that are essential, desirable, and possibly required has increased.

\section{Mongolia}

The number of RTAs, crimes, and road safety violations is on the increase in Mongolia, and this trend is forecast to continue in the future (18). In 2015, JICA launched a project to enhance postgraduate training for health professionals in primary and secondary healthcare facilities. Its aim is to provide customized medical training that is feasible for doctors in Mongolia and sustainable. A major focus of this project is the development of a training system for emergency medicine in primary and secondary healthcare facilities. In 2016, the Advanced Assessment and Life Support (AALS) course was introduced, with assistance from skill simulators and running costs provided by JICA. The course offers comprehensive simulation training with the $\mathrm{ABCDE}$ approach and resuscitation skills in life- threatening situations customized for Mongolian settings. Participants are enthusiastic about implementing, continuing, improving, and disseminating the AALS course on their own. The course is being successfully managed by Mongolian instructors in the Mongolian capital of Ulaanbaatar as well as at the provincial level, and this success has led to other educational programs being developed for nationwide life support training in Mongolia.

\section{Conclusion}

Conducting simulation training customized to individual countries seems to be a highly effective way to transfer knowledge and appropriate skills. TOT programs may play a key role in identifying capable participants and in achieving sustainable development. Whenever possible, training should not merely be conducted in the target country. Rather, training should be conducted in the assisting country and in each target country in turn in order to encourage a more proactive attitude among participants with regard to improving emergency medical services in their home country. Starting and continuing training independently of the assisting country requires initial facilitation and some support in terms of equipment.

\section{References}

1. Rosling H, Rosling O, Ronnlund AR. Factfulness. Sceptre, 
London, UK, 2018.

2. World Health Organization. Global status report on road safety 2018: Summary. https://www.who.int/violence injury_prevention/road_traffic/en/ (accessed January 15, 2020).

3. World Health Organization. Injuries and violence: the facts. https://www.who.int/violence injury prevention/ key_facts/en/ (accessed January 15, 2020).

4. World Health Organization. The global burden of disease: 2004 update. https://www.who.int/healthinfo/ global_burden_disease/2004_report_updatelen/ (accessed January 15, 2020).

5. Nakahara S, Ichikawa M, Kimura A. Population strategies and high-risk-individual strategies for road safety in Japan. Health Policy. 2010; 100:247-255.

6. Ngo AD, Rao C, Hoa NP, Hoy DG, Trang KTQ, Hill PS. Road traffic related mortality in Vietnam: evidence for policy from a national sample mortality surveillance system. BMC Public Health. 2012; 12:561.

7. Nagata T, Takamori A, Kimura Y, Kimura A, Hashizume M, Nakahara S. Trauma center accessibility for road traffic injuries in Hanoi, J Trauma Manag Outcomes. 2011; 5:11-18.

8. Mock C, Lormand JD, Goosen J, Joshipura M, Peden M. Guidelines for essential trauma care. World Health Organization, Geneva, Switzerland, 2004. https://www. who.int/violence_injury_prevention/publications/services/ guidelines_traumacare/en/ (accessed January 15, 2020).

9. Nakahara S, Ichikawa M, Kimura A, Yoshida K. The potential for essential trauma care to empower communities and tackle inequities. World J Surg. 2008; 32:1203-1207.

10. Okada K, Kimura A, Kobayashi K, Inaka A. Evaluation of the trauma care system and suitability of guidelines for essential trauma care in Vietnam. J Jpn Assoc Surg Trauma. 2010; 24:14-320. (in Japanese)

11. Kimura A, Okada K, Kobayashi K, Inaka A, Hagiwara Y, Sakamoto T, Sugimoto N, Nakamura M, Nakamura K, Horiuchi K, Hujii Y, Murota C, Emoto M. Introductory adult cardiac life support course for Vietnamese healthcare workers. Resuscitation. 2008; 79:511-512.

12. Holder Y, Peden M, Krug E, Lund J, Gururaj G, Kobusingye O. Injury surveillance guidelines. World Health Organization, Geneva, Switzerland, 2001. https:// www.who.int/violence_injury_prevention/publications/ surveillance/surveillance guidelines/en/(accessed January 15, 2020).

13. Wada T, Nakahara S, Bounta B, Phommahaxay K, Phonelervong V, Phommachanh S, Mayxay M, Manivong T, Phoutsavath P, Ichikawa M, Kimura A. Road traffic injury among child motorcyclists in Vientiane Capital, Laos: a cross-sectional study using a hospital-based injury surveillance database. Int J Inj Contr Saf Promt. 2017; 24:152-157.

14. Kimura A, Nakahara S, Chadbunchachai W. The development of simple survival prediction models for blunt trauma victims treated at Asian emergency centers. Scandn J Trauma Resusc Emergy Med. 2012; 20:9.

15. Kimura A, Chadbunchachai W, Nakahara S. Modification of the trauma and injury severity score (TRISS) method provides better survival prediction in Asian blunt trauma Victims. World J Surg. 2012; 36:813-818.

16. Community Relations Division, Association of Southeast Asian Nations (ASEAN) Secretariat, ASEAN Regional Road Safety Strategy. ASEAN Secretariat, Jakarta, Indonesia, 2016; pp.10-11. https://asean.org/?static_ post $=$ asean-regional-road-safety-strategy $($ accessed January 15, 2020).

17. Sasser S, Varghese M, Kellermann A, Lormand JD. Prehospital trauma care systems. World Health Organization, Geneva, Switzerland, 2005. https:// www.who.int/violence_injury_prevention/media/ news/04_07_2005/en/(accessed January 15, 2020).

18. Demberelsuren J, Oyunbileg J, Uranchimeg D, Roine M. Road traffic injuries and deaths and their risk factors in Mongolia. Inj Prev. 2016; 22(suppl 2):A172.

Received August 9, 2019; Revised January 17, 2020; Accepted January 28,2020

Released online in J-STAGE as advance publication February 2, 2020.

*Address correspondence to:

Akio Kimura, Department of Emergency and Critical Care, Center Hospital of the National Center for Global Health and Medicine, 1-21-1 Toyama, Shinjuku-ku, Tokyo162-8655, Japan.

E-mail: akimura@hosp.ncgm.go.jp 